\title{
Transcranial direct current stimulation (tDCS) effects on traumatic brain injury (TBI) recovery A systematic review
}

\author{
Ana Luiza Zaninotto ${ }^{1}$, Mirret M. El-Hagrassy², Jordan R. Green ${ }^{1}$, Maíra Babo ${ }^{3}$, \\ Vanessa Maria Paglioni ${ }^{3}$, Glaucia Guerra Benute ${ }^{4}$, Wellingson Silva Paiva ${ }^{3}$
}

\begin{abstract}
Traumatic brain injury (TBI) is a major cause of chronic disability. Less than a quarter of moderate and severe TBI patients improved in their cognition within 5 years. Non-invasive brain stimulation, including transcranial direct current stimulation (tDCS), may help neurorehabilitation by boosting adaptive neuroplasticity and reducing pathological sequelae following TBI. Methods: we searched MEDLINE/PubMed and Web of Science databases. We used Jadad scale to assess methodological assumptions. Results: the 14 papers included reported different study designs; 2 studies were open-label, 9 were crossover randomized clinical trials (RCTs), and 3 were parallel group RCTs. Most studies used anodal tDCS of the left dorsolateral prefrontal cortex, but montages and stimulation parameters varied. Multiple studies showed improved coma recovery scales in disorders of consciousness, and improved cognition on neuropsychological assessments. Some studies showed changes in neurophysiologic measures (electroencephalography (EEG) and transcranial magnetic stimulation (TMS), correlating with clinical findings. The main methodological biases were lack of blinding and randomization reports. Conclusion: tDCS is a safe, non-invasive neuromodulatory technique that can be given as monotherapy but may be best combined with other therapeutic strategies (such as cognitive rehabilitation and physical therapy) to further improve clinical cognitive and motor outcomes. EEG and TMS may help guide research due to their roles as biomarkers for neuroplasticity.
\end{abstract}

Key words: traumatic brain injury, neuronal plasticity, rehabilitation, non-invasive brain stimulation, transcranial direct current stimulation.

EFEITOS DA ESTIMULAÇÃO TRANSCRANIANA POR CORRENTE CONTÍNUA (ETCC) NA RECUPERAÇÃO DO TRAUMATISMO CRANIOENCEFÁLICO (TCE): UMA REVISÃO SISTEMÁTICA

RESUMO. A lesão cerebral traumática (TCE) é uma das principais causas de incapacidade crônica. Menos de um quarto dos pacientes com TCE moderada e grave melhoraram sua cognição dentro de cinco anos. A estimulação cerebral não invasiva, incluindo a estimulação transcraniana por corrente contínua (ETCC), pode ajudar na reabilitação neurológica, aumentando a neuroplasticidade adaptativa e reduzindo as sequelas patológicas após o TCE. Métodos: pesquisamos os bancos de dados MEDLINE / PubMed e Web of Science. Usamos a escala de Jadad para avaliar os métodos utilizados nos ensaios clínicos. Resultados: os 14 artigos incluídos relataram diferentes desenhos de estudo; 2 estudos foram abertos, 9 foram ensaios clínicos randomizados (ECRs) cruzados e 3 foram ECR de grupos paralelos. A maioria dos estudos utilizou a ETCC anódica do córtex pré-frontal dorsolateral esquerdo, mas os parâmetros de montagem e estimulação variaram. Múltiplos estudos mostraram melhoras nas escalas de recuperação de coma em pacientes com distúrbios da consciência e melhora da cognição. Alguns estudos mostraram alterações nas medidas neurofisiológicas (eletroencefalografia (EEG) e estimulação

\footnotetext{
This study was conducted at the Speech and Feeding Disorders Lab, MGH Institute of Health Professions (MGH IHP), Boston, USA
}

${ }^{1}$ Speech and Feeding Disorders Lab, MGH Institute of Health Professions (MGH IHP), Boston, USA. ${ }^{2}$ Neuromodulation Center, Spaulding Rehabilitation Hospital, Harvard Medical School (HMS), Boston, USA. ${ }^{3}$ Hospital das Clínicas, Faculdade de Medicina da Universidade de São Paulo, Department of Neurology, São Paulo, SP, Brazil. ${ }^{4}$ Coordinator of the Psychology Course, Centro Universitário São Camilo, SP, Brazil.

Ana Luiza Zaninotto. Speech and Feeding Disorders Lab, MGH Institute of Health Professions (MGHIHP), 79/96 13th Street, Boston MA, USA. Email: acostazaninotto@mghihp.edu

Disclosure: The authors report no conflicts of interest.

Received July 27, 2018. Accepted in final form April 01, 2019.

\section{(c) BY}


magnética transcraniana (EMT)), correlacionando com os achados clínicos. Os principais vieses metodológicos foram a falta de relatos de cegamento e randomização. Conclusão: a ETCC é uma técnica neuromodulatória segura e não invasiva que pode ser administrada em monoterapia, mas a utilização da ETCC parece impulsionar os resultados clínicos quando combinada com outras estratégias terapêuticas (como reabilitação cognitiva e fisioterapia). 0 EEG e o EMT podem ajudar a orientar a pesquisa e tambem mensurar os ganhos clínicos por serem potenciais biomarcadores da neuroplasticidade. Palavras-chave: traumatismo cranioencefálico, plasticidade neuronal, reabilitação, estimulação cerebral não invasiva, estimulação transcraniana por corrente contínua.

$\mathrm{T}$ raumatic brain injury (TBI) is a major cause of death and chronic disability in industrialized ${ }^{1}$ and developing countries, ${ }^{2}$ particularly for young and elderly patients. TBI can lead to transient or permanent physical, cognitive, affective and/or behavioral deficits. Even mild TBI may cause long-term sequalae such as postconcussion syndrome, ${ }^{3}$ potentially leading to neurological disorders and neurodegeneration. ${ }^{4,5}$ Memory loss is one of the most common deficits following TBI, ${ }^{6-12}$ and cognitive impairment can be persistent, especially after moderate and severe injury, ${ }^{12-16}$ resulting in lower functionality and quality of life. ${ }^{17,18}$ Only $23.7 \%$ of moderate and severe TBI patients (older than 16 years) that received inpatient rehabilitation improved in their cognition within 5 years according to the TBI Model Systems National Database, while $24 \%$ of the sample reported cognitive decline. ${ }^{19}$ Considering its high disease burden and the limited evidence of cognitive rehabilitation's effectiveness in TBI, ${ }^{20}$ there is a great need for new and improved therapeutic strategies.

Neuromodulation, such as non-invasive brain stimulation (NIBS) techniques, promotes adaptive neuroplasticity and may prevent or reduce pathological sequela following TBI. ${ }^{21,22}$ NIBS techniques may improve clinical recovery by facilitating functional and structural neuronal changes, by synaptic strengthening, and by increasing dendritic spines and their connections. ${ }^{23,24}$ NIBS techniques may potentially improve clinical outcomes beyond conventional rehabilitation and help patients who do not respond to typical therapies..$^{25}$ Transcranial direct current stimulation (tDCS) is a safe NIBS technique studied in various disorders, including TBI. ${ }^{22}$ It involves the application of a low intensity electric current (usually 1 to $2 \mathrm{~mA}$ ) often using two electrodes placed over the head to modulate cortical activity. ${ }^{26}$ TDCS alters neuronal resting membrane potentials, thereby raising the likelihood of depolarization and increased underlying cortical excitability, or of hyperpolarization and decreased cortical excitability. ${ }^{24,26}$ Anodal and cathodal tDCS are typically used to increase and decrease excitability respectively, and depending on the montage and stimulation parameters, tDCS can target different cerebral networks, including those involving cognition and motor activity. ${ }^{27,28}$ As tDCS is relatively safe and cost-effective (24) with only transient adverse effects, ${ }^{29,30}$ we aimed to systematically review its utility to improve TBI recovery.

The rationale of this systematic review is that TBI is a complex disorder with limited therapeutic options, and that $\mathrm{tDCS}$ may be a potential adjuvant neurorehabilitation tool to improve clinical outcomes (e.g., cognitive, motor, and level of consciousness) in TBI. Our hypothesis is that tDCS may improve clinical and surrogate outcomes in TBI, depending on stimulation parameters. Our objective is to answer the following PICOS-based research question: does tDCS improve clinical or surrogate outcomes in adult TBI patients in clinical trials?

\section{METHODS}

Our initial online literature search was performed on MEDLINE/PubMed and Web of Science databases. On Pubmed we used the following MeSH terms: ((traumatic brain injury[MeSH Terms]) OR (tbi[MeSH Terms])) AND ((tDCS[MeSH Terms]) OR (Transcranial Direct Current Stimulation[MeSH Terms]) OR (tDCS[MeSH Terms])). We filtered by date (from $1 / 1 / 1900$ to 9/15/2018), Species (Human), and Languages (English). On 9/17/2018 we searched Web of Science for the following search string and filters (TS means Topic): (TS=(traumatic brain injury OR tbi)); timespan: 19002018; indexes: SCI-EXPANDED, SSCI, A\&HCI, CPCI-S, CPCI-SSH, BKCI-S, BKCI-SSH, ESCI, CCR-EXPANDED, IC. We included experimental clinical trials, open label studies and case reports.

Two independent researchers (AZ and MM) reviewed the titles and abstracts. Eligible studies fulfilled the following criteria: experimental studies on adult TBI patients who received tDCS for therapeutic purposes with the primary or exploratory aim of assessing clinical outcomes (e.g., cognitive, motor, or level of consciousness) or surrogate outcomes (e.g., electroencephalogram (EEG), transcranial magnetic stimulation (TMS)), over any duration of time compared to a pre-treatment baseline. We excluded studies that did not meet these criteria, screening first by title, then abstract, then by full text. 
We assessed studies for biases by evaluating funding sources. We used the Jadad score to assess publications based on the quality and reporting of the following methods: randomization ( 0,1 , or 2 score); blinding $(0,1$, or 2 score); and patient flow ( 0 or 1 score); scores range from 0 to 5 and the higher the score the better the publication. ${ }^{31}$ There was generally no need to contact study authors as the necessary data was available, although we did contact one author to clarify blinding methods. ${ }^{32}$ Our methods follow PRISMA guidelines.

\section{RESULTS}

Of 115 search results (56 from Pubmed, 59 from Web of Science), we found 14 studies that used tDCS in TBI patients and fulfilled our eligibility criteria (Figure 1).

The 14 papers included in our review reported different study designs; 2 studies were open-label caseseries $^{33,34}$ and the rest were double-blind randomized clinical trials (RCTs) - 9 crossover RCTs ${ }^{32,35-42}$ one of which was semi-randomized, ${ }^{41}$ and 3 parallel group RCTs. ${ }^{43-45}$ Sample sizes were small, ranging from 5 to 55 participants, and often included other disorders (e.g., anoxia) or healthy controls in addition to TBI. A summary of the 14 papers is presented in Table 1.

\section{Type of outcomes}

The papers reported the use of $\mathrm{tDCS}$ in patients with TBI to improve clinical outcomes (mainly coma recovery and cognitive outcomes) and/or surrogate outcomes such as neurophysiological markers (electroencephalography (EEG) and transcranial magnetic stimulation (TMS)), magnetic resonance spectroscopy (MRS) and functional magnetic resonance imaging (fMRI).

We found 7 studies that used tDCS to improve responsiveness in patients with disorders of consciousness (DOC) due to TBI and other brain injuries. ${ }^{33,35-39,42}$ The only strong evidence of tDCS' effectiveness to improve functionality as measured by Coma Recovery ScaleRevised (CRS-R) came from the same group. All their studies were crossover RCTs using anodal tDCS ( $2 \mathrm{~mA}$, current density $0.571 \mathrm{~A} / \mathrm{m}^{2}$ for 20 minutes) over the left dorsolateral prefrontal cortex (DLPFC) with a right frontopolar reference electrode. ${ }^{35,37,38}$

A study using TMS-EEG ( $\mathrm{n}=4 / 16$ subjects had TBI) reported global excitability increases early on for MCS patients after anodal left DLPFC tDCS; ${ }^{39}$ the authors described significantly increased global mean field amplitudes of the TMS-evoked potentials with $200 \mathrm{~ms}$ of the TMS pulse in MCS patients overall, as opposed to VS patients who also had an increase at up to 100 $\mathrm{ms}$, but a decrease at $300-400 \mathrm{~ms}$. Estraneo et al. ${ }^{36}$ had

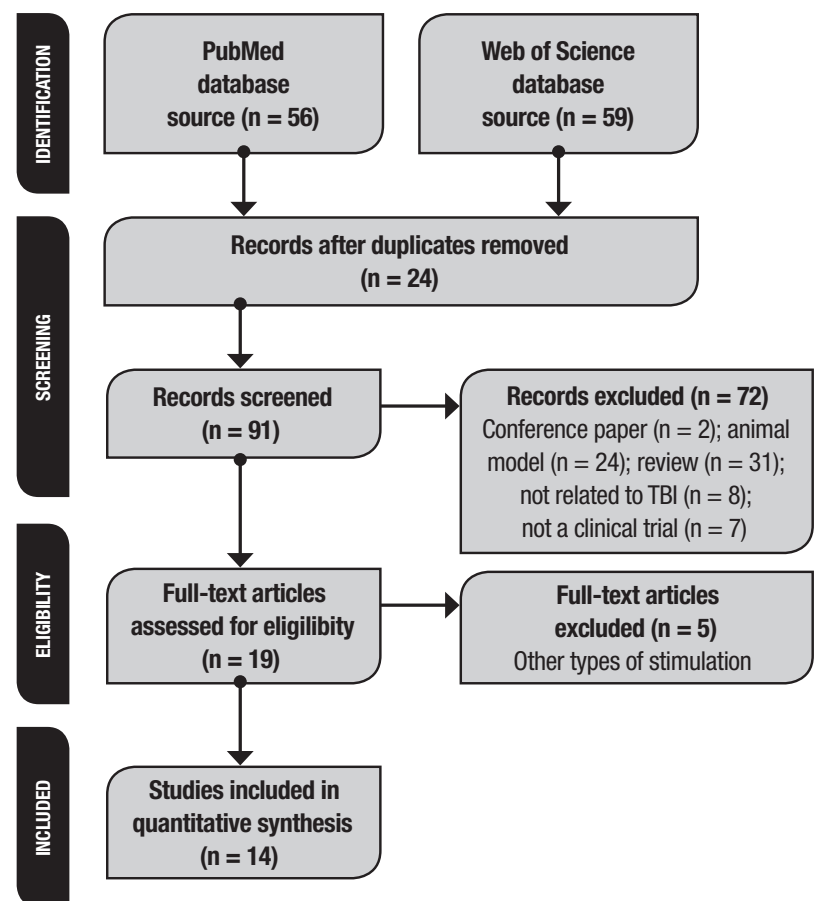

Figure 1. Flow diagram following Prisma Statement.

no positive overall results following left DLPFC anodal tDCS ( $2 \mathrm{~mA}$ over 5 days) on functional (CRS-R) and surrogate (EEG) outcomes. However, this crossover RCT was more heterogeneous than the previous one, ${ }^{37}$ with a mix of subacute and chronic DOC patients.

Six studies used tDCS to improve cognition, $33,40,41,43-45$ four of which showed no differences between outcomes pre and post-intervention. ${ }^{40,41,43,45}$ Two parallel-group sham-control RCTs used offline cognitive training after tDCS. ${ }^{44,45}$ The authors suggested that the combined intervention ( $\mathrm{tDCS}+$ cognitive training) decreased abnormal hyperactivation, measured by fMRI, often seen in TBI patients. ${ }^{44}$ As to the other studies evaluating cognition, one crossover study ${ }^{40}$ found no improvements in RT using the same parameters as those used successfully by Sacco and colleagues ${ }^{44}$ and at a higher current density (due to smaller electrodes). However, they used only 2 sessions, a right orbitofrontal cathode, had no cognitive training and had a small sample size $(n=9)$, which possibly underpowered the results.

Two studies compared cognitive outcomes to EEG outcomes following left DLPFC tDCS: one parallelgroup RCT on subacute TBI reported resting EEG power improvements after one anodal tDCS session (transiently decreased theta slowing at F3), at the end of 10 sessions and the following day (decreased delta plus increased alpha at both F3 and Fp2). It is important to note that this increased normalization (increased physiologic alpha, decreased pathologic delta) occurred under 


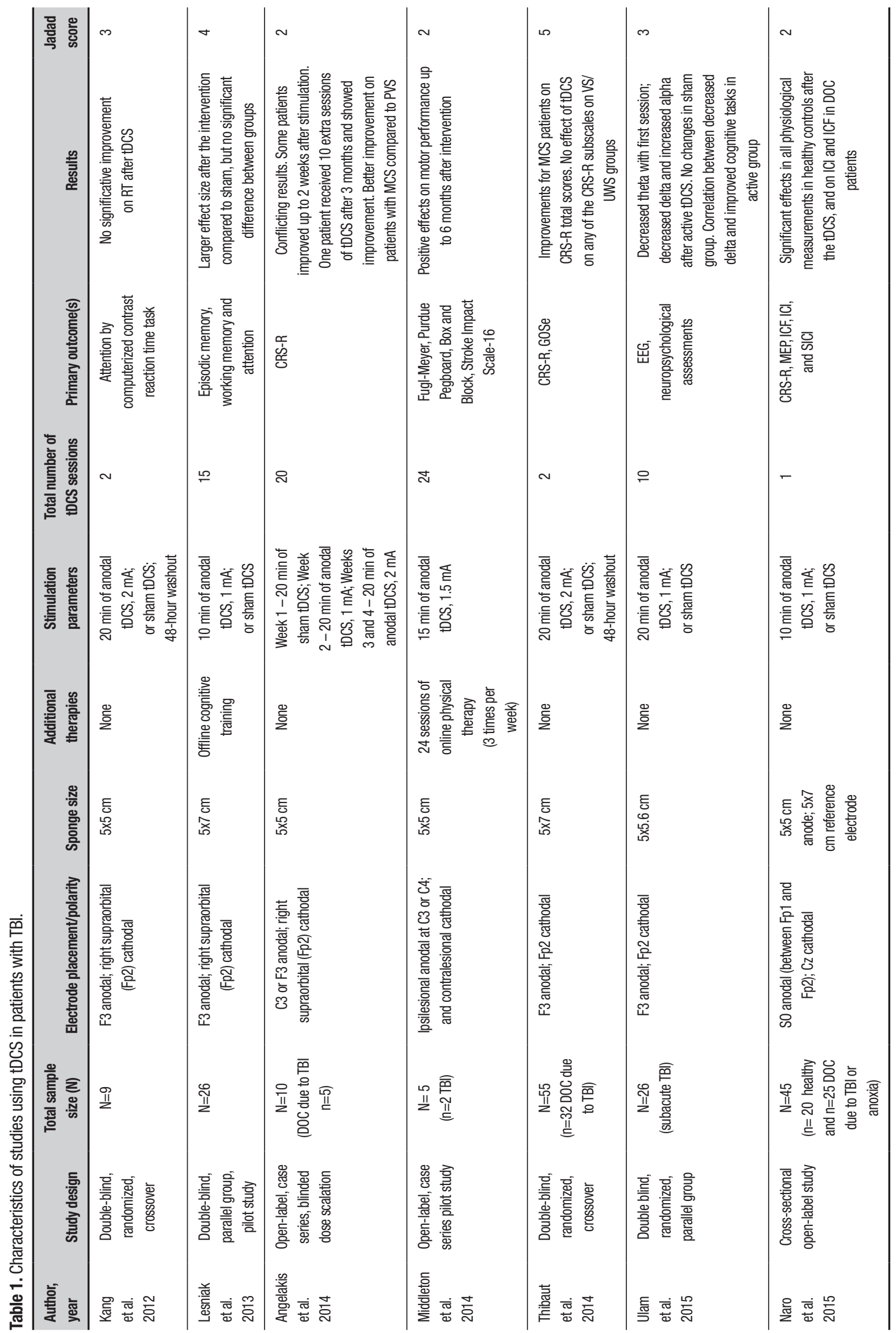




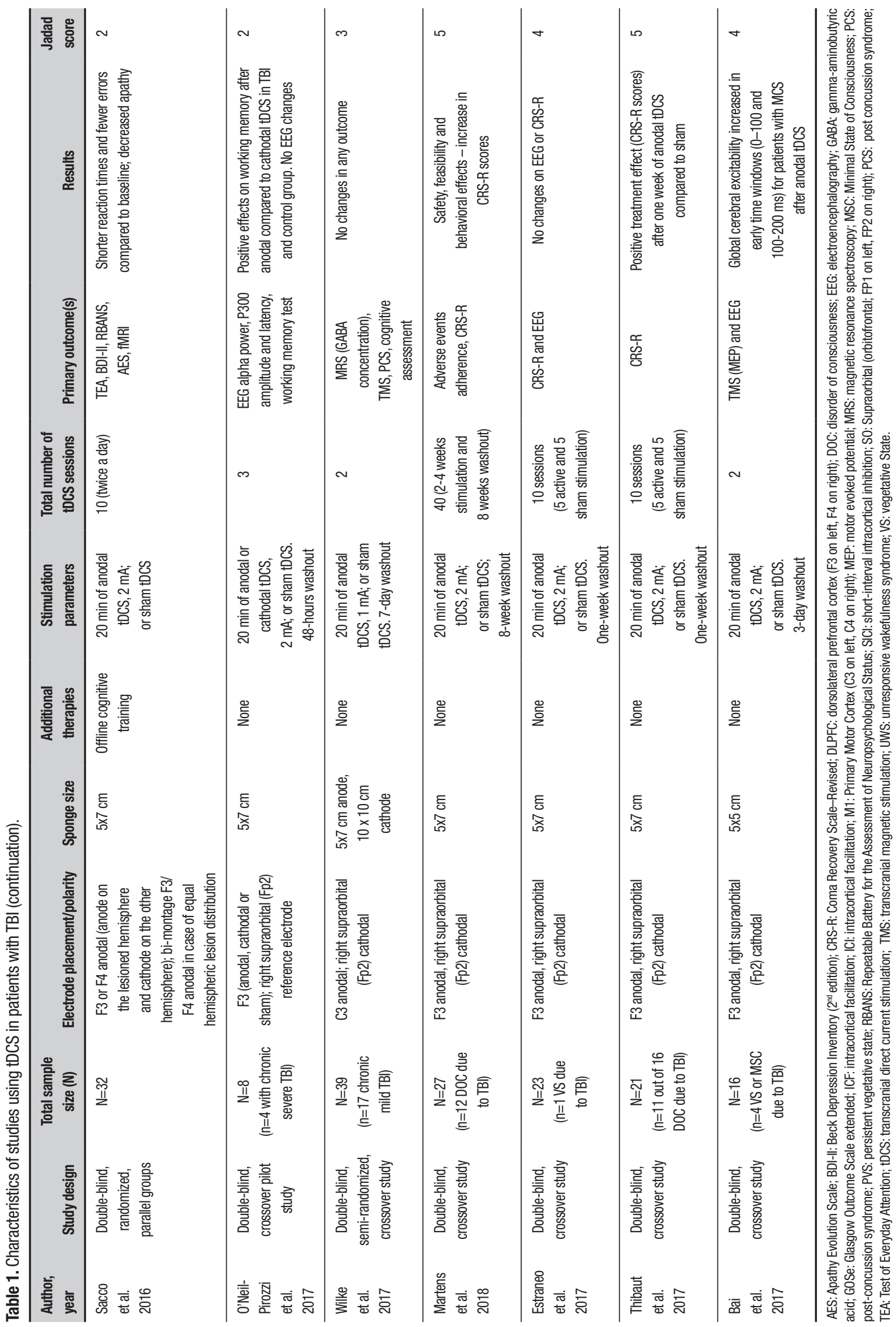


both the Fp2 "cathode" and the F3 "anode". Additionally, the decreased delta power correlated with improved visual accuracy, color word interference, and brief visual memory task..$^{43}$ Meanwhile, the second study was an exploratory crossover RCT, a single session of anodal tDCS increased word recall in both the TBI and control groups; it also increased P300 amplitude (for oddball task performance) in TBI patients. There was no effect on EEG theta or alpha power. ${ }^{33}$

A semi-randomized crossover study hypothesized that TBI patients would have worse cognition and higher GABA concentration and receptor activity than healthy controls, and that anodal left M1 tDCS would help ameliorate these findings. However, they found no changes in cognition, post-concussion syndrome, TMS or magnetic resonance spectroscopy measures, ${ }^{41}$ possibly due to tDCS response variability or variability in their methodology compared to previous studies.

Finally, only one exploratory open-label study analyzed the effects of online tDCS on motor outcomes in patients with stroke and/or TBI. ${ }^{34}$ This study aimed to assess the feasibility and effectiveness of tDCS sessions. The results showed improvements up to 6 months after the intervention, but the interpretation was based on the effect size, which is not standard considering the small sample. ${ }^{34}$ The TBI patients had mixed results.

Methodological scores for clinical trials: We analyzed the quality of the studies using the Jadad score. ${ }^{31}$ Only 3 papers scored 5 out of 5 , having clearly reported the randomization and blinding methods as well as dropouts and withdrawals. Most other studies did not report the method used for randomization, or they were open label studies and scored zero for blinding.

\section{DISCUSSION}

When the brain is injured by trauma or other insults, it attempts to ameliorate the deficits resulting from its injury by forming new cortical and subcortical connections and by reorganizing neural networks. However, these compensatory mechanisms are often suboptimal, unable to fully restore function, and may lead to maladaptive effects and further complications such as cognitive impairment. Non-invasive brain stimulation (NIBS) techniques aim to utilize these neuroplastic mechanisms in ways that might target important functions and thereby improve clinical outcomes and quality of life. In other words, NIBS techniques such as tDCS aim to counteract maladaptive neuroplasticity and promote adaptive changes. The search for efficacious adjuvant therapies to improve outcomes in TBI is critical because rehabilitation techniques, and particularly cognitive rehabilitation, often do not lead to complete recovery.

This review aimed to investigate the question: does tDCS improve clinical or surrogate outcomes in adult TBI patients in clinical trials? Most studies showed evidence of positive outcomes (surrogate and/or clinical) in TBI patients after $\mathrm{tDCS}$ 32-35,37-39,42,44,45 albeit with some methodological variability. Limitations due to heterogeneous procedures are common to rehabilitation studies because the need for tailored therapy makes clinical trial design particularly challenging. Cognition can be especially difficult to target; the exact networks involved in cognitive performance are less clearly delineated than in motor function and are therefore are difficult to target with conventional rehabilitation techniques or with adjuvant therapies such as tDCS. Yet, cognitive problems are a major cause of diminished independence and quality of life in TBI patients, ${ }^{46}$ and they often coincide with - and are confounded by - behavioral and emotional deficits. Any hope for improvement is thus worth investigating. Motor outcomes are also important and merit further investigation in TBI.

Overall the clinical and neurophysiologic results of this systematic review are preliminarily encouraging with regard to coma recovery, cognitive functions and motor recovery in TBI patients. However, further studies are needed to elicit the effects of tDCS parameters, including electrode placement, current density, stimulation duration and interval, as well as its effect on concomitant therapies (and vice versa). Additionally, further studies could help better identify potential tDCS protocol responders based on baseline characteristics.

Considering the risks of polypharmacy in TBI, the potential of tDCS to reduce the need for - and perhaps to counteract the cognitive side effects of - some medications might be very useful. Combining tDCS with cognitive and/or physical training may enhance long-term potentiation (LTP)-like plasticity in the desired region beyond either treatment alone ${ }^{47}$ however, it is important to understand how to use each of tDCS and other therapies to induce neurophysiologic effects individually before their combined effects can be delineated. This is important to avoid reaching a ceiling effect, which is probably what happened in one study. ${ }^{45}$ It may also be possible to obtain synergy by combining tDCS with another treatment, or to use each treatment to target different functions; conversely, targeting the wrong or opposing networks may cancel the therapeutic effects of each treatment.

Improved biomarkers of neural damage due to TBI may help us better understand the mechanisms under- 
lying tDCS and/or other therapies' neurophysiologic effects and may also help clinicians predict their clinical effects and monitor therapy. Our review reveals how EEG and TMS markers preliminarily showed changes in some cases, which did - or did not - correlate to clinical outcomes. TBI is a heterogeneous disorder and anything that helps clinicians eventually tailor therapy or identify responders would be helpful, particularly considering the multiple comorbidities and different types of therapy TBI patients may receive.

TMS can be used as NIBS to promote neuroplasticity when used in a repetitive way (rTMS) or as a biomarker to evaluate the integrity of the corticospinal tract. In our review, the TMS cortical silent period was used to investigate the GABAergic pathway in patients with mild TBI, ${ }^{41}$ and to evaluate DLPFC excitability in patients with disorders of consciousness. ${ }^{39}$ While such surrogate markers have limited generalizability to clinical applications, these measures are becoming increasingly correlated over the years. One example is a study published in 2015, in which the authors found a specific TMS threshold with reliable sensitivity to diagnose early stage amyotrophic lateral sclerosis (ALS) ${ }^{48}$

EEG is the other main biomarker used in our review to assess cortical activity after TBI. EEG is clinically used in TBI (especially when severe), in patients admitted to the intensive care unit, to rule out subclinical seizures, to monitor drug effects, and for other clinical purposes. ${ }^{49,50}$ However, it is not typically used in outpatient settings if there is no history suggestive of seizures. Yet, EEG can be used to follow clinical changes in patients over time even in the presence of medications, as the effects of certain neurological and psychiatric drugs on EEG (e.g., benzodiazepines, etc.) are known. In the context of our review, generalized slowing on EEG is consistent with encephalopathy (if the patient is not sleeping), while pathological focal slowing (especially in the delta range, but also often in the theta range) indicates dysfunction consistent with focal cortical lesions (e.g., stroke, subdural hematoma, abscess, neoplasm, etc.). ${ }^{51}$ Both generalized and focal slowing can variably be seen in TBI patients. Therefore, any decrease in pathological focal slowing is consistent with potentially improved cortical function; for example, in our systematic review, decreased delta power under the electrodes after active tDCS correlated with improved cognitive task performance. Decreased generalized slowing would indicate less or resolved encephalopathy. Eventually, a combination of clinical evaluations, EEG, TMS and/or other neurophysiologic assessments may aid in the development of higher quality tDCS studies in TBI. TMS may be particularly helpful to monitor motor responses.

Overall, the effects of tDCS on clinical outcomes and neurophysiologic markers such as EEG and TMS in TBI patients need to be elucidated in future studies. These studies are worthwhile as heterogeneous disorders require tailored therapy, and tDCS lends itself well to tailoring and individualization based on patient need.

In conclusion, TBI is an unfortunate phenomenon with frequently devastating and heterogeneous clinical outcomes. Cognitive outcomes in TBI are a major source of disability, and few therapeutic options are available. TDCS is a safe, non-invasive neuromodulatory technique that can be given alone (e.g., in comatose patients) but may be best combined with other therapeutic strategies (such as cognitive rehabilitation and physical therapy) to further improve clinical cognitive and motor outcomes. The desired outcomes will have a major impact on networks to target and thus tDCS stimulation parameters and concomitant therapies. The challenges of designing trials for heterogeneous TBI patients necessitate further development of neurophysiologic markers such as EEG and TMS to help track therapeutic progress and guide research.

Authors contributions. All authors contributed significantly to, and approved, the content of this manuscript.

\section{REFERENCES}

1. Bruns $J$ Jr., Hauser WA. The epidemiology of traumatic brain injury: a review. Epilepsia. 2003;44(s10):2-10.

2. de Almeida CER, de Sousa JL, Dourado JC, Gontijo PAM, Dellaretti MA, Costa BS. Traumatic Brain Injury Epidemiology in Brazil. World Neurosurgery. 2016;87:540-7.

3. Bramley H, Hong J, Zacko C, Royer C, Silvis M. Mild Traumatic Brain Injury and Post-concussion Syndrome: Treatment and Related Sequela for Persistent Symptomatic Disease. Sports Med Arthrosc Rev. 2016; 24(3):123-9.

4. Lima DPD, Simao C, Abib SDV, de Figueiredo LFP. Quality of life and neuropsychological changes in mild head trauma - Late analysis and correlation with S100B protein and cranial CT scan performed at hospital admission. Injury. 2008;39(5):604-11.

5. Feltrin FS, Zaninotto AL, Guirado VMP, Macruz F, Sakuno D, Dalaqua

$M$, et al. Longitudinal changes in brain volumetry and cognitive functions after moderate and severe diffuse axonal injury. Brain Inj. 2018; 32(10):1208-17.

6. Sozda CN, Muir JJ, Springer US, Partovi D, Cole MA. Differential Learning and Memory Performance in OEF/OIF Veterans for Verbal and Visual Material. Neuropsychology. 2014;28(3):347-52.

7. Levin HS. Memory deficit after closed-head injury. J Clin Exp Neuropsychol. 1990;12(1):129-53.

8. Tam SF, Man WK. Evaluating computer-assisted memory retraining programmes for people with post-head injury amnesia. Brain Inj. 2004; 18(5):461-70.

9. Kim HJ, Burke DT, Dowds MM, George J. Utility of a microcomputer as an external memory aid for a memory-impaired head injury patient during in-patient rehabilitation. Brain Inj. 1999;13(2):147-50. 
10. Kelly JP. Traumatic brain injury and concussion in sports. JAMA. 1999; 282(10):989-91.

11. Dikmen S, Machamer J, Fann JR, Temkin NR. Rates of symptom reporting following traumatic brain injury. J Int Neuropsychol Society. 2010;16(3):401-11.

12. Godefroy $\mathrm{O}$. Frontal syndrome and disorders of executive functions. J Neurol. 2003;250(1):1-6.

13. Lezak MD, Howieson DB, Bigler ED, Tranel D. Neuropsychological assessment. 5 ed. New York, NY: Oxford University Press; 2012.

14. Costa TL, Zaninotto ALC, Benute GG, De Lucia MCS, Paiva WS, Wagemans $\mathrm{J}$, et al. Perceptual organization deficits in traumatic brain injury patients. Neuropsychologia. 2015;78:142-52.

15. Zaninotto AL, de Paula Guirado VM, Baldivia B, Nunes MD, Oliveira Amorim RL, Teixeira MJ, et al. Improvement of verbal fluency in patients with diffuse brain injury over time. Neuropsychiatr Dis Treat. 2014;10: 1155-60.

16. Zaninotto AL, Vicentini JE, Solla DJ, Silva T, Guirado VM, Feltrin F, et al. Visuospatial memory improvement in patients with diffuse axonal injury (DAl): a 1-year follow-up study. Acta Neuropsychiatr. 2017;29(1):35-42.

17. Schacter LD, Glisky EL, McGlynn SM. The Neuropsychology of Everyday Life: Assessment and Basic Competencies. Boston: Martinus Nijhoff; 1990:231-57.

18. Hoofien D, Gilboa A, Vakil E, Donovick PJ. Traumatic brain injury (TBI) 10-20 years later: a comprehensive outcome study of psychiatric symptomatology, cognitive abilities and psychosocial functioning. Brain Inj. 2001;15(3):189-209

19. Whiteneck GG, Eagye C, Cuthbert JP, Corrigan JD, Bell JM, et al. One and Five Year Outcomes After Moderate-to-Severe Traumatic Brain Injury Requiring Inpatient Rehabilitation: U.S. Department of Health and Human Services Centers for Disease Control and Prevention National Center for Injury Prevention and Control Administration for Community Living (ACL) National Institute on Disability, Independent Living and Rehabilitation Research (NIDILRR); 2018 [Available from: https://www.cdc.gov/ traumaticbraininjury/pdf/CDC-NIDILRR-Self-Report-508.pdf.

20. Cognitive Rehabilitation Therapy for Traumatic Brain Injury: Evaluating the Evidence. http://www.nationalacademies.org/hmd/ /media/Files/ Report\%20Files/2011/Cognitive-Rehabilitation-Therapy-for-TraumaticBrain-Injury-Evaluating-the-Evidence/CRTforTBIreportbrief2.pdf

21. Villamar MF, Portilla AS, Fregni F, Zafonte R. Noninvasive Brain Stimulation to Modulate Neuroplasticity in Traumatic Brain Injury. Neuromodulation. 2012;15(4):326-38.

22. Li SS, Zaninotto AL, Neville IS, Paiva WS, Nunn D, Fregni F. Clinical utility of brain stimulation modalities following traumatic brain injury: current evidence. Neuropsychiatr Dis Treat. 2015;11:1573-86.

23. Pascual-Leone A, Amedi A, Fregni F, Merabet LB. The plastic human brain cortex. Ann Rev Neurosci. 2005;28:377-401.

24. Nitsche MA, Cohen LG, Wassermann EM, Priori A, Lang N, Antal A, et al. Transcranial direct current stimulation: State of the art 2008. Brain Stimul. 2008;1(3):206-23.

25. Lefaucheur JP, Antal A, Ayache SS, Benninger DH, Brunelin J, Cogiamanian $F$, et al. Evidence-based guidelines on the therapeutic use of transcranial direct current stimulation (tDCS). Clin Neurophysiol. 2017; 128(1):56-92.

26. Nitsche MA, Liebetanz D, Lang N, Antal A, Tergau F, Paulus W. Safety criteria for transcranial direct current stimulation (tDCS) in humans. Clin Neurophysiol. 2003;114(11):2220-2.

27. Miniussi C, Ruzzoli M. Transcranial stimulation and cognition. Hand Clin Neurol. 2013:116:739-50.

28. Miniussi C, Harris JA, Ruzzoli M. Modelling non-invasive brain stimulation in cognitive neuroscience. Neurosci Biobehav Rev. 2013;37(8):1702-12.

29. Antal A, Nitsche MA, Kruse W, Kincses TZ, Hoffmann KP, Paulus W. Direct current stimulation over V5 enhances visuomotor coordination by improving motion perception in humans. J Cogn Neurosci. 2004;16(4): $521-7$.

30. Bikson M, Grossman P, Thomas C, Zannou AL, Jiang J, Adnan T, et al. Safety of Transcranial Direct Current Stimulation: Evidence Based Update 2016. Brain Stimul. 2016;9(5):641-61.

31. Jadad AR, Moore RA, Carroll D, Jenkinson C, Reynolds DJ, Gavaghan DJ, et al. Assessing the quality of reports of randomized clinical trials: is blinding necessary? Control Clin Trials. 1996;17(1):1-12.
32. O'Neil-Pirozzi TM, Doruk D, Thomson JM, Fregni F. Immediate memory and electrophysiologic effects of prefrontal cortex transcranial direct current stimulation on neurotypical individuals and individuals with chronic traumatic brain injury: a pilot study. Int J Neurosci. 2017;127(7): 592-600.

33. Angelakis E, Liouta E, Andreadis N, Korfias S, Ktonas P, Stranjalis G, et al. Transcranial Direct Current Stimulation Effects in Disorders of Consciousness. Arch Phys Med Rehabil. 2014;95(2):283-9.

34. Middleton A, Fritz SL, Liuzzo DM, Newman-Norlund R, Herter TM. Using clinical and robotic assessment tools to examine the feasibility of pairing tDCS with upper extremity physical therapy in patients with stroke and TBI: A consideration-of-concept pilot study. Neurorehabilitation. 2014;35(4):741-54.

35. Martens G, Lejeune N, O'Brien AT, Fregni F, Martial C, Wannez S, et al. Randomized controlled trial of home-based 4-week tDCS in chronic minimally conscious state. Brain Stimul. 2018;11(5):982-90.

36. Estraneo A, Pascarella A, Moretta P, Masotta O, Fiorenza S, Chirico $G$, et al. Repeated transcranial direct current stimulation in prolonged disorders of consciousness: A double-blind cross-over study. J Neurol Sci. 2017;375:464-70.

37. Thibaut A, Bruno M-A, Ledoux D, Demertzi A, Laureys S. tDCS in patients with disorders of consciousness. Neurology. 2014;82(13):1112-8.

38. Thibaut A, Wannez S, Donneau AF, Chatelle C, Gosseries O, Bruno MA, et al. Controlled clinical trial of repeated prefrontal tDCS in patients with chronic minimally conscious state. Brain Inj. 2017;31(4):466-74.

39. Bai Y, Xia XY, Kang JN, Yang Y, He JH, Li XL. TDCS modulates cortical excitability in patients with disorders of consciousness. Neuroimage Clin 2017; 15:702-9

40. Kang EK, Kim DY, Paik NJ. Transcranial direct current stimulation of the left prefrontal cortex improves attention in patients with traumatic brain injury: a pilot study. J Rehabil Med. 2012;44(4):346-50.

41. Wilke S, List J, Mekle R, Lindenberg R, Bukowski M, Ott S, et al. No Effect of Anodal Transcranial Direct Current Stimulation on GammaAminobutyric Acid Levels in Patients with Recurrent Mild Traumatic Brain Injury. J Neurotrauma. 2017;34(2):281-290.

42. Naro A, Calabro RS, Russo M, Leo A, Pollicino P, Quartarone A, et al. Can transcranial direct current stimulation be useful in differentiating unresponsive wakefulness syndrome from minimally conscious state patients? Restor Neurol Neurosci. 2015;33(2):159-76

43. Ulam F, Shelton C, Richards L, Davis L, Hunter B, Fregni F, et al. Cumulative effects of transcranial direct current stimulation on EEG oscillations and attention/working memory during subacute neurorehabilitation of traumatic brain injury. Clin Neurophysiol. 2015;126(3):486-96.

44. Sacco K, Galetto V, Dimitri D, Geda E, Perotti F, Zettin M, et al. Concomitant Use of Transcranial Direct Current Stimulation and ComputerAssisted Training for the Rehabilitation of Attention in Traumatic Brain Injured Patients: Behavioral and Neuroimaging Results. Front Behav Neurosci. 2016 31:10:57.

45. Lesniak M, Polanowska K, Seniow J, Czlonkowska A. Effects of Repeated Anodal tDCS Coupled With Cognitive Training for Patients With Severe Traumatic Brain Injury: A Pilot Randomized Controlled Trial. J Head Trauma Rehabil. 2014;29(3):E20-E9.

46. Pagulayan KF, Temkin NR, Machamer J, Dikmen SS. A longitudinal study of health-related quality of life after traumatic brain injury. Arch Phys Med Rehabil. 2006;87(5):611-8.

47. Rogers L. Transcranial Direct Current Stimulation (tDCS): Emerging Uses, Safety and Neurobiological Effects. Neuroscience research progression series: Nova Science Publishers, Incorporated;2016:104

48. Menon P, Geevasinga N, Yiannikas C, Howells J, Kiernan MC, Vucic S. Sensitivity and specificity of threshold tracking transcranial magnetic stimulation for diagnosis of amyotrophic lateral sclerosis: a prospective study. Lancet Neurol. 2015;14(5):478-84.

49. Schmitt S, Dichter MA. Electrophysiologic recordings in traumatic brain injury. Hand Clin Neurol. 2015;127:319-39.

50. Tolonen A, Sarkela MOK, Takala RSK, Katila A, Frantzen J, Posti JP, et al. Quantitative EEG Parameters for Prediction of Outcome in Severe Traumatic Brain Injury: Development Study. Clin EEG Neurosci. 2018;49(4): 248-57.

51. Benbadis S. Focal disturbances of brain function. In: Levin $\mathrm{KH}$, Luders $\mathrm{HO}$, editors. Comprehensive Clinical Neurophysiology. Philadelphia, PA.: Saunders; 2000:457-67. 